\title{
Feasibility of a Mobile Meal Assistance Program for Direct Care Workers in Long-Term Care Facilities in South Korea
}

This article was published in the following Dove Press journal:

Clinical Interventions in Aging

\author{
Dukyoo Jung (D' \\ Jennie C De Gagne $\mathbb{D}^{2}$ \\ Minkyung Lee $\mathbb{D D}^{3}$ \\ Hyesoon Lee $\mathbb{D}^{1}$ \\ Kyuri Lee (D) ${ }^{\prime}$ \\ Eunju Choi $\mathbb{D}^{\prime}$ \\ Juyoun Chung $\mathbb{D D}^{4}$
}

'College of Nursing, Ewha Womans University, Seoul, South Korea; ${ }^{2}$ School of Nursing, Duke University, Durham, NC, USA; ${ }^{3}$ Weill Cornell Medicine, New York, NY, USA; ${ }^{4}$ Department of Comics and Animation Technology, Sejong University, Seoul, South Korea
Correspondence: Minkyung Lee

Weill Cornell Medicine, I 300 York Ave,

New York, NY 10065, USA

$\mathrm{Tel}+\mid$ 9|7-239-6475

Fax + 82-2-3277-2850

Email mkmk8888@naver.com
Purpose: The purpose of this study was to assess the feasibility and examine the preliminary effectiveness of a mobile application-based meal assistant training program (APP) for use by direct care workers (CAs) assisting residents with dementia in long-term care facilities in South Korea.

Methods: We adopted a mixed methods research design, which included a pre- and postintervention study and focus group interviews for the feasibility assessment. Participants included 23 dyads of older adults with dementia and their CAs from a long-term care facility in South Korea. Upon completion of the APP intervention, focused group interviews were conducted with six CAs and five nurses.

Results: The results of paired $t$-tests showed that the effects of the APP intervention on the older adults with dementia and their CAs were not significant; however, the results of the focused group interviews support the potential usefulness of the APP for CAs.

Conclusion: The APP may be applicable to long-term care workers who need meal assistant skills education.

Keywords: dementia, eating, mobile applications, nursing intervention

\section{Introduction}

In 2020, dementia was reported to be the sixth leading cause of death in the United States and the fifth leading cause of death among persons 65 years and older. ${ }^{1}$ Its prevalence is rising, and studies predict that new cases of Alzheimer's disease diagnosed each year in East Asia will increase. ${ }^{2-4}$ In South Korea, more specifically, the number of residents dwelling in long-term care facilities has more than doubled over the past decade due to the increased prevalence of dementia; ${ }^{4}$ approximately $50 \%$ of these residents have been diagnosed with dementia, and over $75 \%$ have cognitive impairment. ${ }^{3,5}$

Adults with dementia exhibit progressive decline in behavioral and cognitive function and ultimately lose the ability to complete activities of daily living without assistance. Studies have found that cognitive ability and physical capability have a significant impact eating performance..$^{6-9}$ Many older adults with dementia report mealtime difficulties, including a loss of perception of the surrounding environment and the inability to use utensils. ${ }^{9-11}$ Distinctive eating behaviors of patients with dementia include clamping one's mouth, refusing to eat, refusing to swallow, spitting out food, and leaving food in one's mouth; these behaviors can increase or necessitate 
dependence on others. ${ }^{9,12}$ Individuals with dementia who have difficulty eating may experience malnutrition, dehydration, aspiration, weight loss, infection, increased morbidity and mortality, and a deteriorating quality of life. ${ }^{9,13,14}$

Long-term care residents with dementia (RWDs) and severe cognitive impairment have reported high deterioration in eating performance within six months of entering a facility. ${ }^{15}$ Researchers have considered multiple factors affecting eating performance of long-term care RWDs, including (a) intrapersonal factors (cognitive function, comorbidity, physical function) $;^{8}$ (b) interpersonal factors (caregivers' knowledge, attitudes, and feeding skills); ${ }^{8,16}$ (c) environmental factors (physical, social, and/or sensory stimulation); and (d) policy perspective factors (staff workload, institutional norms). ${ }^{16}$

Previous studies of effective interventions for mealtime difficulties have focused on nutritional supplements, training of caregivers, feeding assistance, and modification of the environment; ${ }^{17}$ and interventions to stimulate eating performance among RWDs can be grouped into the following categories: training programs, mealtime assistance, environmental modification, and multicomponent intervention. ${ }^{18}$ Mealtime assistance by caregivers has been found to improve eating performance, ${ }^{18}$ and training programs for caregivers have been moderately successful: studies report evidence of longer time eating and decreased feeding difficulty. ${ }^{17}$

Training or education programs for direct care workers (CAs) seek to optimize eating skills of RWDs and improve CA feeding skills ${ }^{17-19}$ because without training, CA feeding behavior may rely on personal habits rather than on evidence-based approaches or scientific guidelines. ${ }^{20}$ Frequent staff shortages at long-term care facilities, however, can make it difficult for CAs to participate in traditional training programs. ${ }^{14}$ While web-based educational programs have been developed for CA training, ${ }^{14}$ busy CAs require more immediate access to information. A personal device with a touchbased user interface is easily accessible anytime and anyplace. Mobile applications have been developed to serve as health education tools for this reason; ${ }^{21,22}$ however, we have found no suitable meal-assistance applications for educating CAs.

The primary aim of this study was to develop a mobile application for RWD meal assistance training and to test the feasibility of its usage by CAs assisting RWDs in long-term care facilities. Our secondary aim was to test the preliminary effectiveness of this intervention on CAs and RWD.

\section{Materials and Methods}

\section{Study Aim and Design}

We used the mixed methods research design with QUAN $\rightarrow$ qual approach; ${ }^{23}$ it included both a pre- and postintervention study with focus group interviews for the feasibility assessment (Figure 1).

\section{Sample and Setting}

We conducted our study in Chungbuk Province, South Korea in a long-term care facility that has 250 residents, 52 CAs, and 18 nurses. RWDs were eligible to participate if they had received a diagnosis of dementia and had lived at the facility for more than six months; RWDs receiving gastrointestinal nutrition or in hospice care due to a terminal illness were excluded. CAs were eligible if they had more than six months of experience in a long-term care facility and possessed (and could use) an Android-based smart phone. We recruited RWDs and CAs who had lived and worked at the facility for more than six months because behavioral and psychological symptoms of dementia or hostility may present in the early stages of institutionalization due to environmental change, ${ }^{8,24,25}$ and newly employed CAs may need time to adapt to their new role in the facility. ${ }^{8,26}$ In addition, as $95 \%$ of Korean adults over 50 own Android-based smart phones, we decided to develop our mobile application for the Android system. ${ }^{27}$ CAs who had received meal care education within the past year were excluded. A sample size of approximately 20 was chosen based on feasibility (the number feasible to recruit within given time) and recommendations for the optimal number for use in a pilot study. ${ }^{28} \mathrm{We}$ considered a minimum sample size of 20 RWD and CA dyads; however given an average $20 \%$ dropout rate, a final sample of 24 dyads was estimated as a goal. Participants were recruited from June 26-July 3, 2019.

\section{APP Intervention Development}

The APP was developed based on previous literature on meal assistance. ${ }^{14,17-19,29}$ A draft of the APP was reviewed by six experts, including long-term care directors and staff nurses, and professors of gerontological nursing. The final version of the APP included four sections: premeal assistance, midmeal assistance, postmeal assistance, and feeding-related issues.

The premeal section included four units: addressing the importance of eating, good feeding posture, utensils for older adults, and exercise for dysphagia prevention. The exercise for dysphagia prevention unit contained three 


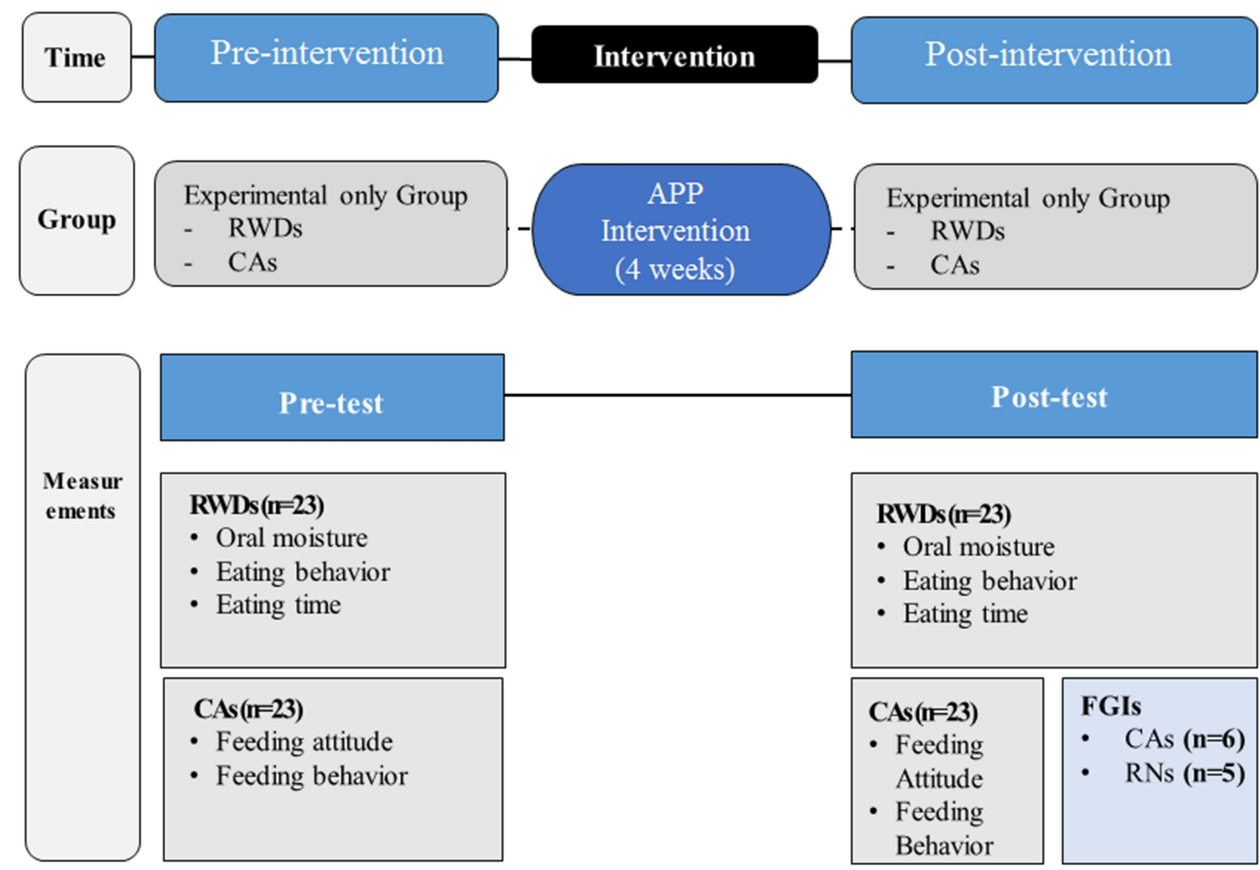

RWD=Residents with dementia, $C A=$ Direct care worker, $\mathrm{APP}=$ Mobile application-based meal assistance training program, FGI=Focus Group Interview, RN=Registered nurse

Figure I Research design.

subcategories: mouth muscle stretching, saliva gland massage, and swallowing. Each exercise lesson provided animated video clips that CAs could apply to their care of RWD.

The midmeal assistance section included two units: meal assistance methods and function-focused meal assistance. The meal assistance methods unit included specific feeding methods, such as spoon-feeding; proper positioning of CAs for feeding assistance; feeding assistance techniques for patients with dysphagia; and emergency treatment for choking. The function-focused meal assistance unit included instruction on maintaining participant function while eating (eg, providing participants with sufficient time to eat, allowing them to eat independently according to their ability, and allowing self-feeding with hands if possible).

The postmeal assistance unit included content pertaining to oral hygiene and the management of unusual eating behaviors (eg, pica, refusal to eat). The aims and methods of oral hygiene after meals were specifically explained. After developing the content of the APP, we built the animation, graphics, design, and template features; a master's level student in computer science built the mobile application. We piloted it with a volunteer group of CAs who were not recruited for the study to assess the readability and accessibility of the developed mobile application. They suggested a larger font size and voice messages, and the mobile application was modified to accommodate their input.

The APP can be downloaded from Google Play Store and the source code is available at open source platform (https://github.com/Jungdukyoo/HowCare).

\section{Intervention Application}

Participating CAs were provided with nine minutes of direct education using PowerPoint; the content of the slideshow was the same as the content of the mobile application. CAs were also provided with directions for using the APP. Researchers and research assistants encouraged CAs to review the information by using the mobile application, and text messages were sent to CAs twice a week for four weeks. Supervising nurses reinforced the study by urging participating CAs to follow the meal assistance program provided by the mobile application. The intervention lasted for four weeks, from July 3-31, 2019.

\section{Data Collection}

\section{Adherence to Intervention}

During the four-week intervention period, APP use data logged on the server (time of opening and content completion rate) were collected to assess CAs' adherence. 
Supervising nurses completed daily behavioral checklists during the intervention period to monitor whether participants provided appropriate meal assistance to RWDs.

\section{Experiences of CAs and RNs}

We conducted two separate focus group interviews to assess feasibility and to gain insight into participants' experiences with the APP; one included six CAs who had participated in the intervention and other included their five supervising nurses. Although the nurses did not participate in the APP intervention, they received the same training as the participants so that they could supervise the CAs' direct care and facilitate their participation in the APP intervention. Furthermore, the nurses monitored whether CAs follow the meal assistance program provided by the APP intervention. All participants agreed to participate by signing an informed consent form. The trained interviewer was not involved in the intervention and had not previously met any of the subjects. The interview began with an open question, followed by specific, semistructured questions. Questions included:

- "What do you think of the APP?"

- "How did your attitudes toward meal assistance for patients with dementia change after using the APP?"

- "What were the benefits of using the APP for both the care workers and residents with dementia?"

- "What would you add to the APP mobile application?"

- "What else would you improve about the APP?"

- "How do you think the APP applies to your facility?"

The interviews were conducted in one session for each group and lasted 90-100 minutes, providing time for each participant to respond freely and fully. Responses that were unclear during the data analysis were clarified by a follow-up telephone call with the participant.

\section{Measures}

Participants' general characteristics included sociodemographic data (gender, age, marriage, education, religion), clinical information (months with facility, underlying disease), and clinical experience (experience in long-term care facilities, number of residents cared for). To assess preliminary effectiveness of the intervention, we collected data regarding RWDs' saliva secretion amounts, eating behavior, and eating duration (time between the onset of eating to completion of eating), and we measured CAs' attitudes and behavior toward feeding RWDs.

RDWs' oral moisture was measured to assess saliva secretion to enhance chewing and swallowing food using the Mucus Life machine ${ }^{30}$ because the APP intervention included an exercise (saliva gland massage and swallowing) for dysphagia prevention. With the tongue extended, a sensor at a constant measuring pressure (about $200 \mathrm{~g}$ ) was placed so that the front of the sensor was perpendicular to the tongue's measuring area (about $10 \mathrm{~mm}$ of the tongue at the tip). It took $2-3$ seconds to receive on-screen scores, which represented the extent of dryness in the oral cavity. The larger the value, the greater the saliva secretion. A score of 29.6 or more was normal, while a score of 28.0-29.5 indicated the oral cavity was slightly dry. If the measured value was 27.9 or less, then the oral cavity was dry. One trained researcher measured oral moisture from $10 \mathrm{AM}$ to $11 \mathrm{AM}$, or from $2 \mathrm{PM}$ to $4: 30 \mathrm{PM}$, avoiding mealtimes. To ensure residents' physical and mental stability, approximately five minutes were given before placing the sensor. In addition, the researcher took three repeated measurements once daily, and we used the median as the measured value to exclude any abnormality caused by the contact angle of the sensor.

This study used a Korean version of the Eating Behavior Scale for elderly people with dementia, developed by Tully et al. ${ }^{31}$ The scale includes a total of six items measuring the ability of patients with dementia to eat, including whether a RWD can initiate eating, maintain attention to meals, locate all the food, use utensils appropriately, bite, chew and swallow without choking, and/or terminate meals. Items are scored on a three-point scale ranging from dependence to independence depending on the level of help needed. A low total score indicates low meal performance and a resulting higher dependence on assistance. A classification score of more than 12 points indicates mild dependence, $6-11$ points indicate moderate dependence, and less than 5 points indicate severe dependence. ${ }^{32}$ Nurses trained to use the Eating Behavior Scale measured all resident participants. In their study, Tully et $\mathrm{al}^{31}$ found the reliability between inspectors was 0.959. In our study, the Cronbach's alpha was 0.907 .

We defined eating time as the average time taken for a resident to complete a meal; it was measured by CA direct observation. Eating time started when a CA began the assisted meal service and ended when the RWD stopped eating. The total eating time was recorded in minutes. 
Each CA's attitude toward feeding was measured using the Formal Caregivers' Attitude toward Feeding Dementia Patients Questionnaire, developed by Chang $^{33}$ and translated into Korean by Hong. ${ }^{7}$ This instrument consists of 20 questions, each scored on a 5-point scale, with answers ranging from 5 ("very much") to 1 ("not very much"). The higher the score, the more negative the caregiver's attitude. Cronbach's alpha was 0.72 at the time of development and 0.73 in Hong's study. ${ }^{7}$ In our study, the Cronbach's alpha was 0.817 .

We measured CA behavior regarding feeding using the Formal Caregivers' Behavior toward Feeding Dementia Patients Observation Checklist developed by Chang $^{33}$ and translated into Korean and revised by Hong. ${ }^{7}$ Hong's tool includes 33 items: 4 on preparing meals for elderly adults with dementia, 3 on environmental preparation, 12 on meal promotion, and 14 on meal assistant skills. We used a modified checklist that included 27 items: 4 on preparing meals, 3 on environmental preparation, 10 on meal promotion, and 10 on meal assistant skills. One item regarding meal assistant skills was not applicable to Korean culture, and five items were not related to the purpose of our study. All questions were answered by five possible responses: $4=$ "always performed," 3 = "frequently performed," 2 = "occasionally performed," 1 = "not performed at all", or "not applicable" (It means that the feeding behavior did not be observed during observation). The higher the final score, the more frequent the feeding behavior. Cronbach's alpha $=0.70$ at the time of development and 0.87 in Hong's study. ${ }^{7}$ In our study, the Cronbach's alpha was 0.880 .

\section{Data Analysis}

Collected data were analyzed using IBM SPSS Statistics 21.0. With adherence to the intervention, completion rate was analyzed with percentage, and the opening time of the APP with mean and standard deviation. Participants' general characteristics and outcome variables were analyzed using percentages, mean, and standard deviations. Matched pair $t$-tests were used to investigate the differences between pretest and posttest for CA data, whereas Wilcoxon signed rank test was used for the nonnormality of RWD data.

A research assistant transcribed the focus group interview recording, and the interviewer reviewed the transcription while listening to the recording. Repeated reading of interview transcripts enabled researchers to identify significant words or phrases. Frequently expressed opinions of the APP were identified, coded, and broken into categories through comparative analysis of similarities and differences. In an iterative coding process, two researchers analyzed the same subset independently and compared codes (triangulation). To ensure inter-coder reliability, any disagreement between coders was resolved through discussion by co-researchers to obtain common opinions. To ensure validity of the participants' intended meaning, the recorded file was transcribed in the primary language of the participants. Relevant feedback was provided by two interviewees (member checking). The analyzed results were reviewed by a qualitative research expert who was not involved in this study.

\section{Ethical Considerations}

This study was approved from the Institutional Review Board of Ewha Womans University for the protection of study participants on May 21, 2019 (No. 201,905-001702). Written consent was obtained from all participants. In the case of patients who could not understand the purpose of the study and determine whether or not to participate, a health-care proxy was given the information and asked to sign the consent. Institutional Review Board approved the procedure of consent. This study was registered in the Clinical Research Information Service (No. KCT0004712).

\section{Results \\ Study Participants}

We identified potentially eligible participants and invited 30 RWDs and 28 CAs to participate. Three RWDs were excluded because they had less than the required six months in residency, and four RWDs were excluded due to terminal illnesses. Two CAs were excluded due to insufficient experience, and two CAs declined to participate. One CA was excluded due to lack of a smart phone; but otherwise, all CAs invited possessed Android-based smart phones. Our final enrollment included $23 \mathrm{CAs}$ and RWDs dyads. There was no drop out between the pretest and posttest, and all participants agreed to participate in our study (Figure 2).

Table 1 shows the general characteristics of the RWD participants. The mean age was $86.09 \pm 5.98$ years, and $34.8 \%$ of RWDs had no formal schooling. Table 2 shows the general characteristics of the CA participants: the mean 
age was $60.83 \pm 6.93$ years, and the majority had a middle school education or higher $(82.6 \%)$. Their mean employment length was $70.78 \pm 41.04$ months, and mean number of residents they assisted was $13.13 \pm 1.01$. The majority of RWDs $(82.6 \%)$ and all CAs were female. The disproportion of participants' gender is due to the facts that $77 \%$ of older adults living LTCs and $94.7 \%$ of CAs are female in Korea. ${ }^{4}$

\section{Adherence to the Intervention}

CAs' average completion rate of the APP was $94.67 \%$, and average opening time of the APP was 124.21 \pm 110.48 minutes. Supervising nurses completed daily behavioral checklists to monitor CAs providing appropriate meal assistance to RWDs, and the completion rate was over $90 \%$. Trained research assistants visited the site once a week to determine whether CAs were using the mobile application and to address questions or issues regarding its use.

\section{Experiences of CAs and RNs}

\section{Satisfaction with the Educational Contents}

CAs reported that the most helpful educational content was "actual meal assistance." The nurses also evaluated this content as being the most useful, specifically giving positive evaluations to the unit that taught about correct meal posture. They provided specific feedback about what they had learned:

- "I had a lot of dementia education, but this time I realized that I had to feed food with spoons from the bottom up. It was comfortable to remove the spoon this way." (CA)

- "I learned a new salivary massage exercise." (CA)

- "I already knew the swallowing movement, but now I know it in more detail." (CA)

- "I do exercises before serving meals, which the older people like. I think it makes elderly adults with dementia feel as though they are cared for, and they feel better." (CA)

- "I realized that elderly residents with dementia usually lean back too much when they are fed. I think [the program] helped a lot because CAs learned a good posture for feeding." (Nurse)

\section{Education Through Mobile Application}

The CAs experienced some initial difficulties learning to use the application, but they overcame them after receiving detailed guidelines and manual training:

\section{RWD}

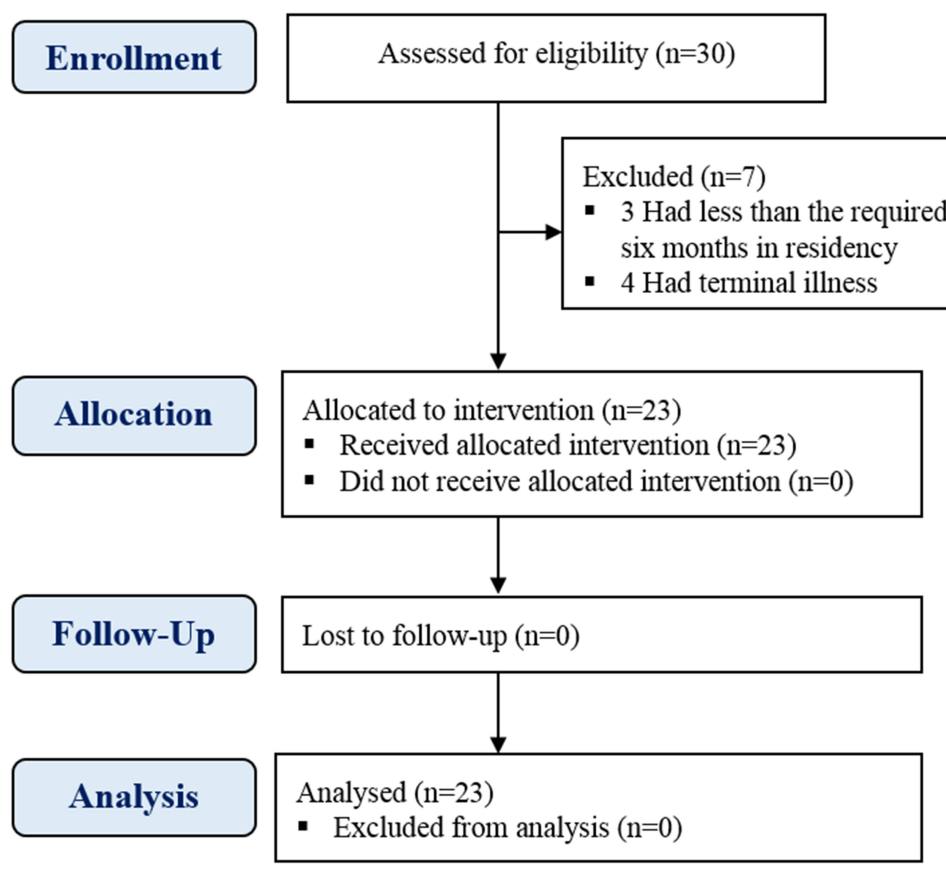

CA

Assessed for eligibility $(\mathrm{n}=28)$

$\mathrm{RWD}=$ Residents with dementia, $\mathrm{CA}=$ Direct care worker

Figure 2 CONSORT flowchart.

Allocated to intervention $(n=23)$

- Received allocated intervention $(n=23)$

- Did not receive allocated intervention $(n=0)$

Analysed ( $\mathrm{n}=23$ )

- Excluded from analysis $(\mathrm{n}=0)$

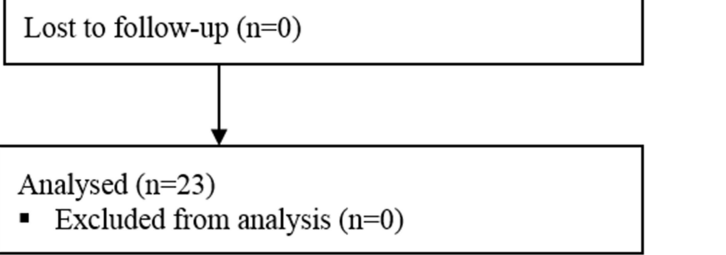


Table I General Characteristics of RWD $(N=23)$

\begin{tabular}{|l|l|}
\hline Characteristics & N (\%)/mean \pm SD \\
\hline $\begin{array}{l}\text { Gender } \\
\text { Male }\end{array}$ & $4(17.4)$ \\
Female & $19(82.6)$ \\
\hline Age (years) & $86.09 \pm 5.98$ \\
\hline Marital Status & \\
Married & $1(4.3)$ \\
Separated & $1(4.3)$ \\
Bereaved & $21(91.3)$ \\
\hline Education level & \\
None & $8(34.8)$ \\
Elementary School & $9(39.1)$ \\
Middle School & $2(8.7)$ \\
High School & $2(8.7)$ \\
$\geq$ College & $2(8.7)$ \\
\hline Religion & \\
Christian & $6(26.1)$ \\
Catholic & $3(13.0)$ \\
Buddhist & $3(13.0)$ \\
Others & 0 \\
None & $11(47.8)$ \\
Months with facility & $34.26 \pm 27.31$ \\
\hline Underlying disease & $3(13.0)$ \\
Stroke & $15(65.2)$ \\
HTN & $7(30.4)$ \\
DM & \\
\hline
\end{tabular}

Abbreviations: HTN, hypertension; DM, diabetes mellitus.

- "It's hard to use [the mobile application] by myself. However, I did not have any trouble after receiving guidance." (CA)

\section{Restrictions of the Mobile Application}

Since CAs have limited time to devote to patient-specific care, they have a limited ability to use the tools in this educational application; applying the recommended assistance in the premeal preparation phase, for example, may not be possible. CAs expressed that it was almost impossible to apply function-focused care and dysphagia prevention exercises to all dementia patients due to a lack of staffing and resources:

- "I do not really have time to sit around and care for each [patient]. The neck exercises and salivary gland massages are good, but we must care for more than 12 people. It will not be possible." (CA)
Table 2 General Characteristics of CAs (N = 23)

\begin{tabular}{|c|c|}
\hline Characteristics & $\mathbf{N}(\%) /$ mean \pm SD \\
\hline \multicolumn{2}{|l|}{ Gender } \\
\hline Male & 0 \\
\hline Female & $23(100)$ \\
\hline Age (years) & $60.83 \pm 6.93$ \\
\hline \multicolumn{2}{|l|}{ Education level } \\
\hline Elementary School & $4(17.4)$ \\
\hline Middle School & $9(39.1)$ \\
\hline High School & $9(39.1)$ \\
\hline$\geq$ College & I (4.3) \\
\hline \multicolumn{2}{|l|}{ Religion } \\
\hline Christian & $9(39.1)$ \\
\hline Catholic & $4(17.4)$ \\
\hline Buddhist & $4(17.4)$ \\
\hline None & $6(26.1)$ \\
\hline Experience in LTC (months) & $70.78 \pm 41.04$ \\
\hline Experience in present LTC (months) & $60.13 \pm 39.58$ \\
\hline Number of residents who were cared for & $13.13 \pm 1.01$ \\
\hline
\end{tabular}

Abbreviation: LTC, long-term care facility.

- "I cannot do everything, including changing their diapers, letting them go to the bathroom, and washing their hands before eating." (CA)

- "If elderly dementia patients were cognitively intact, I could get them to wash their hands or go to the bathroom. However, it is impossible." (CA)

- "It is theoretically right. We must do everything. However, in practice, it is practically impossible." (Nurse)

- "Meal care time will not be much different before and after training. It is impossible to finish it all within working hours." (Nurse)

- "For elderly dementia patients, you cannot actually apply oral care. They swallow everything." (Nurse)

\section{Significance of the APP}

Our mobile application allowed CAs to gain a more professional approach toward RWD feeding and to develop their professional skills. It provided an opportunity to remind them of the importance of meal assistance, a part of their daily work in a facility with an excessive number of patients.

Many CAs lack the opportunity or time for off-line training and recognize that such educational efforts may not be effective in their current work environment. These participants were hopeful that educational applications would help them: 
Table 3 Effects of APP on Dependent Variables of RWD $(\mathrm{N}=23)$

\begin{tabular}{|c|c|c|c|c|}
\hline \multirow[t]{2}{*}{ Variables } & Pretest & Posttest & \multirow[t]{2}{*}{$\mathbf{z}$} & \multirow[t]{2}{*}{$p$} \\
\hline & \multicolumn{2}{|l|}{ Mean \pm SD } & & \\
\hline Oral moisture & $27.48 \pm 3.28$ & $28.74 \pm 3.54$ & -1.617 & 0.106 \\
\hline Eating behavior & $15.48 \pm 4.00$ & $15.87 \pm 4.45$ & -1.714 & 0.087 \\
\hline Eating time (min) & $20.43 \pm 6.20$ & $20.00 \pm 6.74$ & -.508 & 0.611 \\
\hline
\end{tabular}

Table 4 Effects of APP on CAs $(\mathrm{N}=23)$

\begin{tabular}{|l|l|l|l|l|}
\hline \multirow{2}{*}{ Variables } & \multicolumn{2}{l|}{ Pretest } & \multicolumn{1}{l|}{ Posttest } & \multirow{2}{*}{ t } \\
\cline { 2 - 4 } & \multicolumn{2}{|l|}{ Mean \pm SD } & & \\
\hline Attitude & $47.74 \pm 12.42$ & $42.87 \pm 9.15$ & 1.508 & 0.146 \\
Total Behavior & $83.43 \pm 12.61$ & $87.96 \pm 14.11$ & -1.225 & 0.234 \\
Preparation for the residents & $13.74 \pm 2.03$ & $13.13 \pm 2.77$ & 1.058 & 0.302 \\
Environmental preparation & $10.57 \pm 1.67$ & $10.52 \pm 1.73$ & 0.080 & 0.937 \\
Eating encouragement & $32.04 \pm 4.42$ & $34.48 \pm 4.76$ & -1.845 & 0.079 \\
Using feeding skills & $27.09 \pm 7.50$ & $29.83 \pm 7.80$ & -1.363 & 0.187 \\
\hline
\end{tabular}

- "Originally, I was very low on my job as a caregiver. I think it is like being a helper, but ... I've been educated, so I feel more professional and have a different mindset when dealing with seniors." (CA)

- "I always thought I was doing a good job, but the training made me realize that there were a lot of things I did not know. Now I am thinking from the patient's view, trying to make it a bit slower while I am feeding the patient." (CA)

- "A couple of CAs have bad eye vision, so they could not open the mobile application. At first, they told me it bothered them, but they kept looking at the mobile application and grew accustomed to seeing it." (Nurse)

- "Well, RWDs are eagerly waiting for each eating time. I want to assist better, but I know it would be impossible unless government reduces the number of patients per capita." (Nurse)

\section{Preliminary Effectiveness of Intervention}

There were no significant differences between the APP pre- and post-intervention regarding RWD eating behavior, oral moisture, or mealtime length (Table 3). Moreover, there was no significant difference in CA attitudes or knowledge (Table 4).

\section{Discussion}

This study tested the feasibility of a mobile applicationbased meal assistant training program for use by CAs assisting RWDs in long-term care facilities. Focus group interviews indicated that the APP was meaningful and helpful for CAs; they felt that it reinforced the importance of effective feeding assistance for RWDs. The APP provided evidence-based content which CAs found to be effective for improving their attitudes. CAs reported some initial difficulties while learning to use the APP, but they did not have trouble after receiving guidance. Age and educational background may need to be further considered for a more user-friendly design when the mobile application is redesigned. Most CAs working in long-term care facilities in South Korea are in their 50s to $60 \mathrm{~s},{ }^{34}$ and the mean age of CAs who participated in this study was 60.83 . Although $96 \%$ of people in their 50 s, and $77 \%$ of those older than 60 , own a smartphone in South Korea, it is reported that older adults continue to have some challenges using smartphone apps, ${ }^{27}$ therefore, if CAs initiate and use the APP by themselves without faceto-face education, they may not utilize the APP effectively. Future research should develop detailed but accessible instructions that can be disseminated for use of the APP by CAs.

Nurses who supervised CAs who participated in the study stated that some older CAs with limited eyesight had trouble opening the APP and clicking the contents. We suggest increasing font size, changing font type for readability, and making the spaces between text and icons larger so that users can click the correct items more easily. 
Push notifications, reminders, and alarms can be added to improve adherence to the APP.

The APP included four sections: premeal, midmeal, and postmeal assistance, and feeding-related issues. CAs stated that although the educational content was helpful and its application theoretically desirable, applying every recommended method of care to RWDs would be impossible due to a lack of time and staffing. CAs could become overwhelmed or discouraged by excessive educational content during a short period, and thus, in future revisions, we will consider choosing content that is both essential and more applicable for CAs caring for large numbers of RWDs. The current content, however, could be feasible for family caregivers who have fewer time restraints than nursing staff.

This study examined the preliminary effectiveness of the APP on the eating behavior, oral moisture, and eating time of RWDs; and it examined CAs' attitudes and knowledge toward feeding RWDs. CAs directly assist RWDs with eating every day in South Korea, but they lack opportunities to learn about specific methods of feeding assistance and often rely on previous experience or personal habits. ${ }^{14,16}$ The aim of the APP development and application in our study was to improve CA feeding skills and to encourage the maintenance of positive attitudes towards meal assistance for RWDs. This study did not, however, show significant effects of the APP on RWDs and CAs.

Inconsistent findings are reported throughout the literature $^{7,14,33,35}$ regarding whether participation in staff education is significantly related to RWD eating behavior or eating time. ${ }^{7,14,33,35}$ Previous studies have shown significant effects of caregiver educational programs on $\mathrm{CA}$ knowledge, behavior, and attitudes. ${ }^{7,33,35}$ In comparison with previous studies, ${ }^{7,33,35}$ our study provided hands-on CA training; however, our APP may not have been effective due to the short intervention duration. Previous studies have applied at least 6 - to 12 -week interventions ${ }^{7,14,35}$ to verify the effects of feeding intervention on older adults. In addition, since cognitive function and physical capabilities of RWDs are common factors that may influence eating behaviors of RWDs, ${ }^{8}$ these factors need to be collected and controlled in future studies to examine the effectiveness of intervention.

In the current study, the APP was not significantly effective in increasing CA feeding attitudes and behaviors, which was congruent with the findings of previous studies. ${ }^{7}$ In Hong and Gu's study, ${ }^{7}$ the feeding intervention program for caregivers based on lecture and lab showed a significant effect on the knowledge and behavior of feeding, but not on the attitudes toward feeding. Our study's short duration may not have provided enough time for CAs to become familiar with the new technology or to adjust to the use of a mobile application; therefore, we speculate that attitude modification needs to be given more time before being compared with knowledge and behavior modification. Moreover, Liu et $\mathrm{al}^{18}$ reported that interaction between older adults with dementia and CAs is recommended to improve feeding-related attitudes of CAs. When the modification of our intervention is considered, role-play could be considered as a good way to enhance positive engagement and dyadic interaction or to increase empathy between older adults and CAs.

We used the translated version of measurements, which may not be ideally applicable to Korean long-term care facilities. Moreover, we omitted several items from the original measurement as they were not related to Korean long-term care facilities. Reliable and validated measurements should be developed and used in the future study.

\section{Conclusions}

Feeding assistance for older adults with dementia should rely on evidence-based skills that maintain independent feeding behavior when possible. To achieve this goal, CAs require continued training. The findings from this study support the potential usefulness of the evidencebased feeding skill program for CAs with the mobile application. In the future study, researchers will (a) use randomization with a larger sample and comparison group in more LTC settings and in other settings, (b) consider the variables and measurements to control predictors and examine the effectiveness of the intervention, (c) ensure that the APP is continuously modified with a more userfriendly design, and (d) develop a detailed and accessible manual and measures to help users utilize the APP effectively.

\section{Acknowledgment}

The authors thank Dr Donnalee Frega for her assistance in editing and proofreading the manuscript.

\section{Funding}

National Research Foundation of Korea (NRF) grants funded by the Korea government (No. 201713030011, 2020R1A2C1013713). 


\section{Disclosure}

The authors report no conflicts of interest in this work.

\section{References}

1. Alzheimer's Association; Thies W, Bleiler L. 2020 Alzheimer's disease facts and figures. Alzheimers' Dement. 2020;16(391-460).

2. Prince M, Ali G-C, Guerchet M, Prina AM, Albanese E, Wu Y-T. Recent global trends in the prevalence and incidence of dementia, and survival with dementia. Alzheimer's Res Ther. 2016;8(1):23. doi:10.1186/s13195-016-0188-8

3. Ministry of Health and Welfare, National Institute of Dementia. 2018 Korea dementia observatory; 2018 Available from: https://www.nid. or.kr/info/dataroom_view.aspx?bid=188.

4. Ministry of Health and Welfare. Status of elderly welfare facilities; 2019 Available from: http://kosis.kr/statHtml/statHtml.do?orgId= $117 \&$ tblId=DT_117N_B00003\&conn_path=I2.

5. Ministry of Health and Welfare, Korea Institue for Health and Social Affairs. Plan for production and management system of dementia related statistics; 2018 Available from: http://www.mohw.go.kr/react/ jb/sjb030301vw.jsp?PAR_MENU_ID $=03 \& M E N U \_I D=$ 032902\&CONT_SEQ $=347400$ \&page $=1$.

6. Lee J, Ryu SA. Factors associated with feeding difficulty in long-term care facility older adults with dementia. $J$ Korean Gerontol Nurs. 2017;19(1):1-12. doi:10.17079/jkgn.2017.19.1.1

7. Hong $\mathrm{H}, \mathrm{Gu} \mathrm{M}$. Development and effects of a coping skill training program for caregivers in feeding difficulty of older adults with dementia in long-term care facilities. J Korean Acad Nurs. 2018;48 (2):167-181. doi:10.4040/jkan.2018.48.2.167

8. Liu W, Galik E, Boltz M, Nahm ES, Lerner N, Resnick B. Factors associated with eating performance for long-term care residents with moderate-to-severe cognitive impairment. $J$ Adv Nurs. 2016;72 (2):348-360. doi:10.1111/jan.12846

9. Chang -C-C, Roberts BL. Feeding difficulty in older adults with dementia. J Clin Nurs. 2008;17(17):2266-2274. doi:10.1111/j.13652702.2007.02275.x

10. Murphy JL, Holmes J, Brooks C. Nutrition and dementia care: developing an evidence-based model for nutritional care in nursing homes. BMC Geriatr. 2017;17. doi:10.1186/s12877-017-0443-2

11. Slaughter SE, Hayduk LA. Contributions of environment, comorbidity, and stage of dementia to the onset of walking and eating disability in long-term care residents. J Am Geriatr Soc. 2012;60 (9):1624-1631. doi:10.1111/j.1532-5415.2012.04116.x

12. Aselage MB, Amella EJ, Watson R. State of the science: alleviating mealtime difficulties in nursing home residents with dementia. Nurs Outlook. 2011;59(4):210-214. doi:10.1016/j.outlook.2011.05.009

13. Hanson LC, Ersek M, Lin FC, Carey TS. Outcomes of feeding problems in advanced dementia in a nursing home population. $J \mathrm{Am}$ Geriatr Soc. 2013;61(10):1692-1697.

14. Batchelor-Murphy M, Amella EJ, Zapka J, Mueller M, Beck C. Feasibility of a web-based dementia feeding skills training program for nursing home staff. Geriatr Nurs (Minneap). 2015;36 (3):212-218. doi:10.1016/j.gerinurse.2015.02.003

15. Carpenter GI, Hastie CL, Morris JN, Fries BE, Ankri J. Measuring change in activities of daily living in nursing home residents with moderate to severe cognitive impairment. BMC Geriatr. 2006;6(1):7. doi:10.1186/1471-2318-6-7

16. Liu W, Tripp-Reimer T, Williams K, Shaw C. Facilitators and barriers to optimizing eating performance among cognitively impaired older adults: a qualitative study of nursing assistants' perspectives. Dementia (London). 2018.
17. Liu W, Cheon J, Thomas SA. Interventions on mealtime difficulties in older adults with dementia: a systematic review. Int J Nurs Stud. 2014;51(1):14-27. doi:10.1016/j.ijnurstu.2012.12.021

18. Liu W, Galik E, Boltz M, Nahm ES, Resnick B. Optimizing eating performance for older adults with dementia living in long-term care: a systematic review. Worldviews Evid Based Nurs. 2015;12 (4):228-235. doi:10.1111/wvn.12100

19. Batchelor-Murphy MK, McConnell ES, Amella EJ, et al. Experimental comparison of efficacy for three handfeeding techniques in dementia. $J$ Am Geriatr Soc. 2017;65(4):e89-e94. doi:10.1111/jgs. 14728

20. Aselage MB, Amella EJ. An evolutionary analysis of mealtime difficulties in older adults with dementia. $J$ Clin Nurs. 2010;19(1-2):33-41. doi:10.1111/j.1365-2702.2009.02969.x

21. Subhash TS, Bapurao TS. Perception of medical students for utility of mobile technology use in medical education. Int $J$ Med Public Health. 2015;5(4).

22. Mohapatra DP, Mohapatra MM, Chittoria RK, Friji MT, Kumar SD. The scope of mobile devices in health care and medical education. Int $J$ Adv Med Health Res. 2015;2(1):3. doi:10.4103/23494220.159113

23. Creswell JW, Clark VL. Designing and Conducting Mixed Methods Research. 2nd ed. Thousand oaks: SAGE Publications, Inc.; 2011.

24. Lee GE. A grounded theory approach to the adjustment process of the institutionalized elderly: the control of reluctance. J Korean Acad Nurs. 2002;32(5):624-632. doi:10.4040/jkan.2002.32.5.624

25. Oh BH. Diagnosis and treatment for behavioral and psychological symptoms of dementia. $J$ Korean Med Assoc. 2009;52 (11):1048-1054. doi:10.5124/jkma.2009.52.11.1048

26. Jo J, Kim Y. A phenomenological study on the adaptation experience of care-workers for caring elderly patients. J Korean Acad Soc Womens Health. 2007;8(2):1-27.

27. Gallup Korea. 2012-2018 Smartphone use; 2018. Available from: https://panel.gallup.co.kr/Contents/GallupReport/\%ED\%95\%9C\%EA $\% \mathrm{~B} 5 \% \mathrm{AD} \% \mathrm{EA} \% \mathrm{~B} 0 \% \mathrm{~A} 4 \% \mathrm{~EB} \% 9 \mathrm{~F} \% \mathrm{BDG}$ allupReport(20180808) $\%$ EC $\% 8 \mathrm{~A} \% \mathrm{~A} 4 \% \mathrm{~EB} \% \mathrm{~A} 7 \% 88 \% \mathrm{ED} \% 8 \mathrm{~A} \% \mathrm{~B} 8 \% \mathrm{ED} \% 8 \mathrm{~F} \% \mathrm{~B} 0$.pdf.

28. Hertzog MA. Considerations in determining sample size for pilot studies. Res Nurs Health. 2008;31(2):180-191. doi:10.1002/ nur. 20247

29. Liu W, Jao YL, Williams K. The association of eating performance and environmental stimulation among older adults with dementia in nursing homes: a secondary analysis. Int J Nurs Stud. 2017;71:70-79. doi:10.1016/j.ijnurstu.2017.03.004

30. Fukushima Y, Yoda T, Araki R, et al. Evaluation of oral wetness using an improved moisture-checking device for the diagnosis of dry mouth. Oral Sci Int. 2017;14(2):33-36. doi:10.1016/S1348-8643(17) 30017-4

31. Tully MW, Matrakas KL, Muir J, Musallam K. The eating behavior scale: a simple method of assessing functional ability in patients with Alzheimer's disease. J Gerontol Nurs. 1997;23(7):9-15. doi:10.3928/ 0098-9134-19970701-08

32. Lee K, Song J. Characteristics of eating behavior in elders with dementia residing in long-term care facilities. $J$ Korean Acad Nurs. 2012;42(4):466-476. doi:10.4040/jkan.2012.42.4.466

33. Chang CC, Lin LC. Effects of a feeding skills training programme on nursing assistants and dementia patients. J Clin Nurs. 2005;14 (10):1185-1192. doi:10.1111/j.1365-2702.2005.01240.x

34. Welfare MoHa. 2019 Status of long-term care service; 2020. Available from: http://www.mohw.go.kr/react/modules/download. jsp?BOARD_ID $=140 \& C O N T$ SEQ $=353801 \&$ FILE_SEQ $=283347$.

35. Chen LL, Li $\mathrm{H}$, Lin R, et al. Effects of a feeding intervention in patients with Alzheimer's disease and dysphagia. J Clin Nurs. 2016;25(5-6):699-707. doi:10.1111/jocn.13013 


\section{Publish your work in this journal}

Clinical Interventions in Aging is an international, peer-reviewed journal focusing on evidence-based reports on the value or lack thereof of treatments intended to prevent or delay the onset of maladaptive correlates of aging in human beings. This journal is indexed on PubMed Central, MedLine, CAS, Scopus and the Elsevie
Bibliographic databases. The manuscript management system is completely online and includes a very quick and fair peer-review system, which is all easy to use. Visit http://www.dovepress.com/ testimonials.php to read real quotes from published authors. 